\title{
ANALISIS PERBEDAAN BREASTFEEDING EFFICACY SEBELUM DAN SETELAH DIBERIKAN TEKNIK RELAKSASI AUTOGENIC TRAINING
}

\author{
Ayi Diah Damayani ${ }^{1}$, Tesza Rezky Permata ${ }^{2}$, Nandini Parahita Supraba ${ }^{3}$ \\ 1,2,3) Poltekkes Kemenkes Pangkalpinang \\ teszapermata@gmail.com
}

\begin{abstract}
ABSTRAK
Pemberian ASI Eksklusif dipengaruhi oleh banyak faktor, salah satunya adalah kesiapan ibu dalam memberikan ASI. Tingginya pernikahan dini di Indonesia berdampak pada peningkatan risiko secara fisik dan psikologis yang dapat mengganggu proses menyusui. Salah satu cara untuk menanggulanginya adalah dengan meningkatkan rasa percaya diri ibu dalam memberikan ASI yang dapat dilakukan dengan berbagai cara. Salah satunya teknik relaksasi dengan metode autogenic training yang dapat menurunkan rasa cemas dan meningkatkan rasa nyaman ibu. Teknik ini dapat dilatih pada ibu yang baru melahirkan dengan metode yang sederhana. Tujuan penelitian ini adalah untuk menganalisis perbedaan breastfeeding self efficacy sebelum dan setelah diberikan teknik autogenic training di Kabupaten Bangka Barat.Adapun manfaatnya dapat digunakan sebagai data dasar dalam pengambilan kebijakan terkait peningkatan cakupan ASI eksklusif di Provinsi Bangka Belitung. Penelitian ini dapat dijadikan acuan untuk mengadakan pelatihan teknik relaksasi bagi pasangan muda agar memiliki breastfeeding self efficacy. Penelitian ini adalah penelitian rancangan one group pre-post test design. Pengumpulan data dilakukan bulan Agustus - Oktober 2019 pada 30 orang ibu hamil trimester 3 yang tinggal di wilayah Kabupaten Bangka Barat, mengikuti pelatihan autogenic training dan hamil normal. Data hasil penelitian dianalisis menggunakan Paired T-Test. Berdasarkan hasil prates terdapat 31 responden $(77,5 \%)$ dengan breastfeeding self efficacy kategori cukup, sedangkan pada hasil pascates terdapat 40 responden (100\%) dengan breastfeeding self efficacy kategori baik. Hasil analisis menunjukkan terdapat perbedaan yang signifikan breastfeeding self efficacy sebelum dan sesudah diberikan teknik relaksasi autogenik training.
\end{abstract}

Kata kunci : ASI, autogenic training, breastfeeding efficacy, teknik relaksasi

\section{Abstract}

Exclusive breastfeeding is influenced by many factors, one of which is the readiness of the mother to give breast milk. The high rate of early marriage in Indonesia has an impact on increasing physical and psychological risks that can interfere with the breastfeeding process. One way to overcome this is by increasing the mother's confidence in breastfeeding which can be done in various ways, one of which is the relaxation technique with the autogenic training method which can reduce anxiety and increase the mother's comfort. This technique can be trained on new mothers with a simple method. The purpose of this research is to analyze the difference breastfeeding self-efficacy before and after given autogenic training techniques in West Bangka.This research can be used as primary data in policy-making to improve exclusive breastfeeding in Bangka Belitung province. This research also can be used as a reference to conduct relaxation techniques training for young couples to have breastfeeding self-efficacy. This study is a one-group pre-post test design. Data collection was carried out in August - October 2019 on 30 trimesters three pregnant women, living in West Bangka Regency, attending autogenic training and healthy pregnancy. Research data were analyzed using Paired T-Test. Based on the pre-test results, there were 31 respondents (77.5\%) with the Breastfeeding Self 
Efficacy category sufficient. While the post-test results, there were 40 respondents (100\%) with Breastfeeding Self Efficacy in the excellent category. The analysis showed that there were significant differences in Breastfeeding Self Efficacy before and after the Autogenic Relaxation Training Technique.

Keywords: autogenic training, breastfeeding, breastfeeding efficacy, relaxation technique

\section{PENDAHULUAN}

Keluarga merupakan pilar penting dalam meningkatkan derajat kesehatan bangsa. Keluarga yang berkualitas diharapkan dapat berkontribusi nyata dalam mewujudkan bangsa yang maju dan beradab. Penelitian Maholtra (2011) mencatat bahwa jumlah anak di bawah usia 18 tahun di Indonesia yang menikah mencapai 22,0\%. United Nations Fund for Population Activities (UNFPA) (2012) memperkirakan bahwa pada tahun 2020 terjadi peningkatan pernikahan usia dini dan setiap tahunnya mencapai 14,2 juta. Paling banyak pernikahan dini berlangsung di negara - negara berkembang termasuk Indonesia.

Secara Nasional, Riset Kesehatan Dasar Tahun (2013) menyebutkan bahwa terdapat 2,6\% perempuan menikah pertama kali pada usia kurang dari 15 tahun dan 23,9\% menikah pada usia 15 - 19 tahun. Adapun 5 Provinsi dengan tingkat persentasi pernikahan dini tertinggi adalah Kalimantan Tengah, Jawa barat, Kalimantan Selatan, Bangka Belitung dan Sulawesi Tengah. Hal ini menunjukkan bahwa secara nasional Bangka Belitung dengan peringkat ke 4 memiliki tugas dan tanggung jawab untuk menurunkan angka pernikahan dini di masyarakat.Dampak dari pernikahan dini yang terjadi adalah kehamilan remaja yang secara nyata meningkatkan risiko secara fisik dan psikologis bagi ibu dan bayi yang dikandungnya.Remaja yang hamil memiliki risiko untuk melahirkan secara prematur sehingga dengan pemberian ASI eksklusif diharapkan tumbuh kembang bayi dapat berjalan dengan optimal (Minarni et al., 2014).

Pemberian ASI eksklusif dipengaruhi oleh banyak faktor, salah satunya adalah kesiapan ibu dalam memberikan ASI. Selain memberikan manfaat fisik (nutrisi), ASI eksklusif juga memberikan manfaat sosial dan psikologis bayi (Marzida et al., 2016). Berdasarkan penelitian Pollard dan Guil (2009), terdapat korelasi positif antara nilai dasar efikasi diri pada ibu menyusui dan lama pemberian ASI pada 6 bulan postpartum, yang artinya semakin tinggi efikasi diri maka akan semakin lama pemberian ASI. Menurut Dennis (2010) bahwa berberapa faktor yang dapat memengaruhi tingkat efikasi diri seorang ibu dalam hal menyusui (Breastfeeding Self-Efficacy), yaitu: pengalaman orang lain (melihat orang lain menyusui), pengalaman diri sendiri (proses menyusui sebelumnya), dan dukungan suami dalam menyusui.

Peningkatan rasa percaya diri ibu dalam memberikan ASI dapat dilakukan dengan berbagai cara, baik dari segi motivasi, nutrisi, dukungan keluarga maupun dukungan sosial. Proses persalinan dapat menimbulkan rasa ketidaknyamanan yang dapat mempengaruhi tingkat kecemasan ibu dalam memberikan ASI eksklusif pada awal masa nifas(Rahayu, 2018). Untuk itu salah satu cara yang dapat dilakukan adalah dengan melakukan teknik relaksasi dengan metode autogenic training yang dapat menurunkan rasa cemas dan meningkatkan rasa nyaman ibu. Teknik ini dapat dilatih pada ibu yang baru melahirkan dengan metode yang sederhana (Juanita, 2013).

Penelitian ini bertujuan untuk menganalisis perbedaan breastfeeding self efficacy sebelum dan setelah diberikan teknik autogenic training. Selanjutnya penelitian ini dapat memberikan alternatif relaksasi dengan 
mengidentifikasi perbedaan breastfeeding self efficacy sebelum dan setelah diberikan teknik autogenic training. Selain itu, penelitian ini diharapkan dapat memberikan dukungan terhadap program pemerintah untuk lebih meningkatkan mutu pelayanan bagi ibu dan bayi, terutama dalam peningkatan cakupan ASI eksklusif dan pemahaman kesehatan reproduksi.

\section{METODOLOGI}

Penelitian ini adalah penelitian rancangan one group pre-post test design yaitu penelitian dengan satu kelompok subyek yang dilakukan perlakuan/ intervensi yang dilakukan pengukuran sebelum dan sesudah perlakuan. Pengumpulan data dilakukan di Kabupaten Bangka Barat Bangka Belitung dari bulan Agustus - Oktober 2019. Sampel pada penelitian ini adalah ibu muda yang menikah di usia muda (15 - 20 tahun), hamil trimester 3, tinggal di wilayah Kabupaten Bangka Barat, mengikuti autogenic training dan hamil normal sejumlah 40 orang. Instrumen yang digunakan adalah breastfeeding self efficacy scale, rekaman autogenic training dan lembar monitoring. Seluruh data yang diperoleh, dicatat dan ditabulasi. Data hasil penelitian akan menggunakan analisis Paired $T$-Test di SPSS 24.0 .

\section{HASIL}

Penelitian ini dilaksanakan selama dua bulan mulai 28 Agustus 2019 hingga 26 Oktober 2019 di Kabupaten Bangka Barat yaitu Puskesmas Kelapa dan Tempilang mengenai analisis perbedaan breastfeeding efficacy sebelum dan sesudah pemberian teknik autogenik training di Kabupaten Bangka Barat. Adapun karakteristik responden dapat dilihat pada tabel 1 berikut.

Tabel 1. Hasil Analisis Univariat

\begin{tabular}{lcc}
\hline Variabel & $\mathbf{n}$ & $\mathbf{\%}$ \\
\hline Usia & & \\
$<20$ & 3 & 7,5 \\
\hline
\end{tabular}

\begin{tabular}{lcc}
\hline Variabel & $\mathbf{n}$ & $\mathbf{\%}$ \\
\hline $20-35$ & 36 & 90,0 \\
$>35$ & 1 & 2,5 \\
Pekerjaan & & \\
Tidak Bekerja & 39 & 97,5 \\
Bekerja & 1 & 2,5 \\
\hline
\end{tabular}

Data breastfeeding efficacy diukur dua kali yaitu sebelum diberikan teknik autogenic training dan sesudahnya. Data disajikan dengan mean \pm SEM. Setelah proses tabulasi, dilakukan uji normalitas data menggunakan Shapiro-Wilk dengan SPSS 24.0, hasilnya didapatkan kedua data yaitu breastfeeding efficacy baik sebelum maupun sesudah autogenic training memiliki data normal $(p>0.05)$. Uji hipotesis dilakukan dengan Paired T Test dan terdapat perbedaan yang signifikan breastfeeding efficacy sebelum dan sesudah diberikan autogenik training $(\mathrm{p}<0.05)$. Adapun perbedaan rerata keduanya dapat dilihat pada diagram 1 berikut.

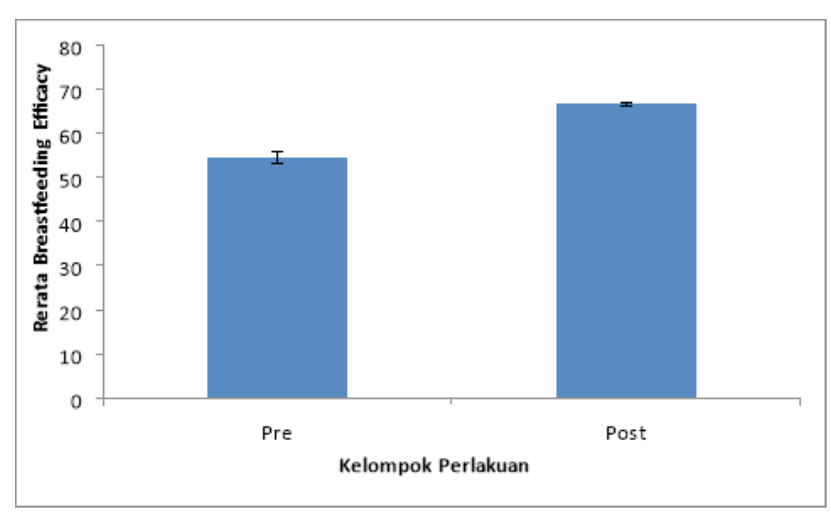

\section{Gambar 1. Rerata Breastfeeding Efficacy sebelum dan sesudah dilakukan teknik aurogenic training}

\section{PEMBAHASAN}

Hasil penelitian menunjukkan bahwa sebanyak 36 responden (90\%) berusia $20-35$ tahun. Hasil penelitian juga menunjukkan bahwa sebanyak 39 responden (97,5\%) tidak bekerja. Dapat disimpulkan bahwa sampel pada penelitian ini homogen. Pendidikan yang lebih tinggi akan berpengaruh pada semakin 
luasnya pandangan individu tentang segala hal, banyaknya pengetahuan yang dimiliki, dan mudah menerima ide atau cara baru dalam kehidupannya. Pendidikan juga dapat dikaitkan dengan pekerjaan (Purwanto, 2014).

Penelitian ini bertujuan untuk menganalisis perbedaan Breastfeeding Self Efficacy sebelum dan sesudah diberikan Teknik Relaksasi Autogenic Training di Kabupaten Bangka Barat. Berdasarkan hasil prates, terdapat 31 responden $(77,5 \%)$ dengan Breastfeeding Self Efficacy kategori cukup, sedangkan pada hasil pascates, terdapat 40 responden (100\%) dengan Breastfeeding Self Efficacy kategori baik. Berdasarkan hasil analisis yang telah dilakukan, diperoleh hasil $(p<0.05)$. Hal ini menunjukkan bahwa terdapat perbedaan yang signifikan breastfeeding self efficacy sebelum dan sesudah diberikan teknik relaksasi autogenic training sehingga dapat disimpulkan bahwa hipotesis penelitian diterima.

Menyusui bayi pada tahun pertama kehidupan bayi merupakan strategi efektif untuk mempromosikan kesehatan dan menghindari morbiditas di negara berkembang (Heymann et al., 2013). Pemberian asi eksklusif pada 6 bulan pertama kemudian merupakan standar normatif dalam pemberian makanan pada bayi. Di lain sisi, $60 \%$ wanita berhenti menyusui bayinya lebih awal dari yang mereka inginkan. Saat ini telah banyak penelitian yang menggarisbawahi pentingnya variabel psikologi dalam pemberian ASI secara berkelanjutan. Salah satu faktor psikologi ini adalah self efficacy atau kepercayaan diri yang merupakan faktor unik yang dapat dimodifikasi dan dapat menjadi desain intervensi dalam meningkatkan pemberian ASI eksklusif. Ibu dengan kepercayaan diri yang lebih tinggi pada awal postpartum akan lebih lama durasi menyusui dan lebih banyak yang memberikan ASI secara eksklusif (Hinic, 2016).

Gangguan kecemasan yang sering terjadi pada wanita postpartum dapat mengganggu breastfeeding self efficacy, oleh karena itu ibu nifas membutuhkan teknik relaksasi yang dapat mengurangi tingkat kecemasan serta meningkatkan kepercayaan diri ibu dalam hal menyusui. Teknik autorelaksasi yang dikenal dengan istilah autogenic training, merupakan salah satu teknik relaksasi selain yoga, guided imagery, taichi, pilates, cakra dan meditasi (Dossey dan Keegan, 2009).

Autogenic Training (AT) merupakan standar intervensi keperawatan yang telah terdaftar di Nursing Intervention Classification (NIC) dan telah digunakan secara luas dalam intervensi keperawatan untuk mengatasi kecemasan dalam berbagai situasi dengan tingkat evidencebased level 1 (Ackley, 2008). AT memiliki teknik relaksasi yang relatif sederhana, mudah dan tidak memerlukan baju khusus atau gaya tubuh yang sulit, jika dibandingkan dengan teknik relaksasi yang lain, (Vidas, M., Smalc, V.F., Catipovic, M., \& Kisik, 2011).

Peningkatan kepercayaan diri ibu dalam hal memberikan ASI eksklusif secara tidak langsung akan membantu ibu untuk menentukan tindakan yang diperlukan apabila ada hambatan atau kesulitan saat proses menyusui berlangsung serta bereaksi positif dalam menghadapi kesulitan tersebut (Albery, 2011). Dengan adanya efikasi diri yang meningkat setelah pemberian teknik relaksasi autogenik traning maka akan dapat mempengaruhi tingkat keberhasilan menyusui.

\section{SIMPULAN DAN SARAN}

Berdasarkan hasil penelitian analisis perbedaan breastfeeding self efficacy sebelum dan sesudah diberikan teknik relaksasi autogenic training di Kabupaten Bangka Barat, maka dapat disimpulkan bahwa terdapat perbedaan yang signifikan breastfeeding self efficacy sebelum dan sesudah diberikan teknik relaksasi autogenic training yaitu sebelum diberikan teknik relaksasi 
autogenik training dengan $(\mathrm{p}<0.05)$.

Perlu adanya program pemberian teknik relaksasi autogenic training pada ibu menyusui baik itu dilakukan di rumah pasien, puskesmas, maupun rumah sakit untuk meningkatkan breastfeeding self efficacy. Peran aktif keluarga sangat diharapkan agar ibu sehat secara fisik dan psikologis serta bayi mendapat cukup ASI yang sangat berguna untuk tumbuh kembangnya.

\section{DAFTAR PUSTAKA}

Ackley, B.J., 2008. Evidence-Based Nursing Care Guidelines: Medical-Surgical Interventions, MosbyElsevier, Amsterdam.

Albery, 2011. Psikologi Kesehatan Panduan Lengkap dan Komprehensif Bagi Studi Psikologi Kesehatan, Palmall, Yogyakarta.

Balitbang Kemenkes, R.I., 2013. Riset kesehatan dasar; RISKESDAS. Jakarta: Balitbang Kemenkes RI, 2013, hal.110-119.

Dossey, B. dan Keegan, L., 2009. Holistic nursing: A handbook for practice, Jones \& Bartlett Learning.

Heymann, J., Raub, A. dan Earle, A., 2013. Breastfeeding policy: a globally comparative analysis. Bulletin of the world health organization, 91, hal.398406.

Hinic, K., 2016. Predictors of breastfeeding confidence in the early postpartum period. Journal of Obstetric, Gynecologic \& Neonatal Nursing, 45(5), hal.649-660.

Juanita, F., 2013. Relaksasi autogenic training untuk membantu keberhasilan masa awal laktasi pada ibu postpartum. Jurnal Ners, 8(2), hal.283-294.

Malhotra, A., Warner, A., McGonagle, A. dan
Lee-Rife, S., 2011. Solutions to end child marriage. Washington, DC: International Center for Research on Women.

Marzida, M., Nugraha, D.P. dan Johandika, M.W., 2016. Kesiapan Ibu Hamil Terhadap Pemberian Asi Eksklusif. Jurnal Kesehatan Samodra Ilmu, 7(2), hal.167-175.

McCarter-Spaulding, D.E. dan Dennis, C., 2010. Psychometric testing of the breastfeeding self-efficacy scale-short form in a sample of black women in the United States. Research in nursing \& health, 33(2), hal.111-119.

Minarni, M., Andayani, A. dan Haryani, S., 2014. Gambaran Dampak Biologis Dan Psikologis Remaja Yang Menikah Dini Di Desa Munding Kecamatan Bergas Kabupaten Semarang. Jurnal Keperawatan Anak, 2(2), hal.95-101.

Pollard, D. dan Guill, M., 2009. The relationship between baseline self-efficacy and breastfeeding duration. Southern online journal of nursing research, 9(4), hal.1-6.

Purwanto, M., 2014. Psikologi pendidikan., Remaja Rosdakarya, Bandung.

Rahayu, D., 2018. Hubungan Breastfeeding Self Efficacy Dengan Keberhasilan Pemberian ASI Eksklusif. Jurnal Ilmu Kesehatan, 7(1), hal.247-252.

UNFPA, H., 2012. Ageing in the twenty-first century: A celebration and a challenge. London and New York.

Vidas, M., Smalc, V.F., Catipovic, M., \& Kisik, M., 2011. The Application of Autogenic Training in Counseling Center for Mother and Child in Order to Promote Breastfeeding. Collegium Antropologicum, hal.723-73. 
